\title{
NORDIC MODEL: WHAT MAKES SCANDINAVIA SO SPECIAL
}

\author{
Alexander Mechitov, University of Montevallo, Montevallo, Alabama, U.S.A.
} Helen Moshkovich, University of Montevallo, Montevallo, Alabama, U.S.A.

dx.doi.org/10.18374/JABE-21-1.3

\begin{abstract}
The paper studies the peculiarities of the socio-economic development of Scandinavian countries. Authors briefly outline country profiles of all five Nordic countries: Denmark, Finland, Iceland, Norway, and Sweden, and concentrate on characteristics that distinguish them from other Western countries. These characteristics include good educational systems, hi-tech economies, effective healthcare, a high level of social protection, and stable political systems. The paper highlights two important cultural peculiarities of Scandinavian countries, which include egalitarianism and a high level of social trust in Nordic countries. Authors specifically analyze the role and history of gender equality and emphasize the active and positive role of local labor unions. The paper concludes that the so-called Nordic way of life successfully combines the main positive features of capitalistic and socialistic socio-economic models and proposes a right balance between free-market economic effectiveness and human equality principle.
\end{abstract}

Keywords: Scandinavia, Nordic model, welfare state, social policy, social democracy, social equality 